\title{
Where Do Cultural Omnivores Come From? The Implications of Educational Mobility For Cultural Consumption*
}

\author{
Tak Wing Chan \\ Department of Social Science \\ UCL Institute of Education
}

\author{
Heather Turner \\ Department of Statistics \\ University of Warwick
}

May 29, 2017

\begin{abstract}
Many scholars see social mobility as a key factor that contributes to the emergence of cultural omnivores. In this paper, we discuss three versions of the social mobility argument and assess their empirical validity using recent survey data on music and visual arts consumption in the UK. By applying diagonal reference models to our data, we show that none of these three arguments receives empirical support. Both parents' and respondent's educational level affect music/visual arts consumption, with the weight of the former being about a third in magnitude of the latter. There is no difference between the upwardly mobile and the downwardly mobile in the relative weights of origin and destination. Finally, socially mobile individuals are actually less omnivorous than those who are intergenerationally stable in advantaged positions. In light of these findings, we argue that social mobility does not explain the emergence of music/visual arts omnivores in the UK.
\end{abstract}

*Early versions of this paper were presented at the Spring 2014 meeting of the ISA RC28, the 2015 annual meeting of the American Sociological Association, the 2015 Understanding Society scientific conference, and in seminars in Dublin, Hong Kong, London, Paris, and Stockholm. We thank audiences of those meetings, and David Firth, Sam Friedman, John Goldthorpe, Lorraine Waller for helpful comments. The research reported in this paper is supported by a British Academy Research Development Award. 


\section{Background and research question}

Recent research on the social stratification of cultural consumption has consistently shown that although individuals in advantaged social positions are more likely than others to consume highbrow culture, they do not have any general aversion against other cultural forms. Indeed, consumers of highbrow culture are just as likely to consume middlebrow or popular culture, leading Peterson and Simkus (1992) to describe them as cultural omnivores. ${ }^{1}$

But where do cultural omnivores come from? Broadly speaking, there are two complementary views, which we label as the cultural democratisation argument and the social mobility argument respectively. The first view says that the emergence of cultural omnivores reflects a general democratisation of culture which, in turn, can be traced to a range of long-term social structural, cultural, and institutional changes.

On social structural change, Peterson and Kern (1996, p. 905) argue that with growing affluence, rising educational level, broader curriculum, and the gradual fusion of the arts and the media, highbrow culture has become more accessible and, correspondingly, less of a status marker. Similarly, Van Eijck (1999, p. 310) notes that advertisers use arts to market commercial products, and art institutions employ marketing techniques in order to reach larger audiences. Thus, 'mass culture, commerce, and the arts have become more and more intertwined, resulting in a blurring of the boundaries between these domains.'

On cultural trends, Peterson and Kern (1996, p. 905) argue that in the aftermath of the Second World War, and as a direct consequence of the horror of Nazism, overt discrimination and prejudice based on race, religion, etc. have become untenable. This can be seen as part of a broader trend towards greater tolerance of other cultures (Inglehart, 1990). Historians have also documented a long-term decline in deference (Runciman, 1997, pp. 153158). Supercilious attitudes, or at least their public expression, have become less acceptable (Chan and Goldthorpe, 2004).

Furthermore, the art-world itself has changed. In the past, royal academies of arts defended the particular aesthetic standard that they endorsed. But the "market forces that swept through all the arts brought in their wake new aesthetic entrepreneurs who propounded ... new and ever more exotic modes

\footnotetext{
${ }^{1}$ See also Peterson and Kern (1996), Van Eijck (2001), López-Sintas and García-Álvarez (2002), Bunting et al. (2008), Bennett et al. (2009), and Chan (2010). It should be noted that often a majority, or at least a substantial minority, of individuals in advantaged social position do not consume highbrow culture at all (see e.g. Peterson, 1992; Chan and Goldthorpe, 2007b). By implication, cultural omnivores tend to be a small minority of high status groups, let alone of the general population.
} 
of expression' (Peterson and Kern, 1996, p. 905). Whatever merits these competing aesthetic claims might have individually, their joint impact is to undermine the idea that there is a single artistic standard. In this way, institutional changes in the art-world also promote a more inclusive, omnivorous attitude (see also Peterson, 1992).

The various strands of the cultural democratisation argument sketched above all suggest that cultural boundaries are weakening. In contrast, although the social mobility argument does not preclude the blurring of cultural categories, it does not require it either. Instead, it is premised on individuals crossing (possibly fixed) cultural boundaries. One version of the social mobility argument goes as follows. Socially mobile individuals were brought up in the cultural milieu of their family of origin. But, as adults, they move in quite different social and cultural circles. Because of their diverse cultural exposure, mobile individuals are more likely to be culturally omnivorous than those who are intergenerationally stable in their social positions. And since there has been substantial social mobility, in the absolute sense and mainly upward in direction, in all industrial societies over much of the twentieth century (Erikson and Goldthorpe, 1992), this could explain the emergence of cultural omnivores in many societies over the past few decades.

It should be clear that the cultural democratisation argument and the social mobility argument are not mutually exclusive. Both could be true. In this paper, we focus on the latter, partly because the social mobility argument is better-defined and thus more directly testable. More importantly, the social mobility argument is widely accepted by scholars in the field. But, as we will demonstrate below, this view is not supported by empirical evidence.

\subsection{Three versions of the social mobility argument}

Both Peterson and Kern (1996) and Van Eijck (1999) regard social mobility as an important contributing factor to the emergence of cultural omnivores. Similarly, Lahire (2008, p. 174) maintains that 'individual mobility ... often translate[s] into a heterogeneity of cultural practices and preferences.' And in a study of tastes in comedy, Friedman (2012, p. 467) 'find[s] omnivorousness only within one social group - the upwardly mobile.'

Although many scholars are in agreement that social mobility contributes to cultural omnivorousness ${ }^{2}$ closer inspection reveals three different versions of the social mobility argument. The first refers to a composition effect. This suggests that social mobility changes the composition of high status

\footnotetext{
${ }^{2}$ Apart from the authors cited or quoted in the main text, Ultee and de Graaf (1991), and Daenekindt and Roose (2013a,b, 2014) also make similar claims that social mobility explains the emergence of cultural omnivores.
} 
groups, but not the consumption behaviour of high status individuals. As Van Eijck (1999, p. 311) suggests, 'the higher educated has become more heterogeneous because its members are recruited from increasingly diverse social backgrounds ... high-status groups may be composed of increasingly different people rather than increasingly omnivorous people' (emphasis in the original). If this is true, the nouveau riche would still restrict their cultural consumption to middlebrow or popular genres, while the 'old money' would remain highbrow snobs. It is only when they are viewed as a group that high status people appear to be culturally omnivorous. Van Eijck (1999) himself is not committed to this argument which, as he points out, is directly testable with individual-level data. In particular, this view implies that the social origin of individuals completely determines their cultural consumption pattern, with destination playing little or no role.

Alternatively, the experience of social mobility might actually change the taste and behaviour of individuals. In his study of comedy tastes, Friedman (2012, p. 467) posits that 'lowbrow comedy taste is established during childhood but highbrow tastes are added as cultural capital grows.' Coulangeon (2015, p. 55) argues that 'socially mobile people face, at least potentially, a higher variety of cultural influences across their life course than non-mobile people, they are consequently expected to be more diverse in their cultural choices and practices.' In other words, social mobility leads to cultural omnivorousness because mobile individuals are exposed to more diverse cultural milieus. Perhaps this is what most scholars have in mind when they speak of social mobility effects on cultural consumption. This view implies that both origin and destination play a non-negligible role in shaping cultural consumption. But, crucially, because it is diverse exposure that leads to cultural omnivorousness, it also implies that upwardly mobile individuals are more omnivorous than those who are immobile in high status positions. For example, first-generation university graduates should be more omnivorous than second-generation graduates.

As regards the third version of the social mobility argument, consider this early statement of Duncan (1966, p. 91): 'one is not entitled to discuss "effects" of mobility ... until he has established that the apparent effect cannot be due merely to a simple combination of effects of the variables used to define mobility.' In Duncan's view, then, to speak of social mobility effects, we need to establish not only the main effects of origin and destination, but also their interaction effect (i.e. particular combinations of origin and destination) on the outcome of interest. ${ }^{3}$ An example of such interaction effect,

\footnotetext{
${ }^{3}$ Although Duncan's argument is widely accepted, there is a technical debate about the best way to specify the interaction effect (see e.g. Hope, 1975, 1981; Sobel, 1981, 1985).
} 
regarding the class-vote association in the UK, concerns a possible asymmetry between upward and downward mobility. Clifford and Heath (1993, p. 51) suggest that "the downwardly mobile ... retain the values and behaviour patterns of their class of origin, whereas the upwardly mobile are assimilated ... into the social networks and culture of their class of destination.' In other words, social origin is more salient for the downwardly mobile than for the upwardly mobile. The result is that mobile individuals, whether they move upwards or downwards, are likely to vote Conservative. This is analogous to the 'status maximisation' hypothesis of Daenekindt and Roose (2013a,b, 2014) in which socially mobile individuals behave, culturally speaking, as the immobiles in either their origin or destination category, whichever is higher. We refer to this as the asymmetry argument. In Section 3 below we will explain how we test these three versions of the social mobility argument.

\section{Data and measures}

The data that we use come from a household panel survey from the UK called Understanding Society. It was launched in 2009 and, at the time of writing, six waves of data are available for analysis. ${ }^{4}$ Understanding Society is still a young panel survey. But it is well suited to addressing our research question, firstly, because it has a very large sample and, when appropriate sampling weights are applied, the data is representative of the UK population. More importantly, wave 2 of the survey contains a cultural consumption module. In this paper, we focus on music and visual arts consumption. Following Chan and Goldthorpe (2007a,b), we restrict our analysis to respondents aged 20 to $64(N=28,657)$.

It is now commonly accepted by statisticians and applied researchers alike that Sobel's diagonal reference models, which we use in this paper, provide a cogent and helpful way to test social mobility effects. Cox (1990), for example, sees in this class of models a close correspondence between the statistical model and the sociological phenomenon of interest. Houle and Martin (2011) point out that, if origin and destination are quantitative variables (say, years of schooling) and mobility is parameterised as their difference, then there would be an identification problem if origin, destination and mobility are all included in the model. But the diagonal reference models, being non-linear in nature, provide a way to overcome this identification problem.

${ }^{4}$ All individuals aged 16 or over in the sampled households are interviewed each year. Individuals leaving their household are followed, and all adult members of their new household are also interviewed. Data collection of each wave, using computer assisted personal interviewing, lasts 24 months, such that the second wave of data collection started in January 2010 and finished in January 2012. Respondents of the British Household Panel Survey (BHPS) are incorporated into the Understanding Society sample from wave 2. See www. understandingsociety.ac.uk for details. 
Table 1: Percentage of Understanding Society respondents aged 20-64 who have been to music or visual arts events in the past 12 months $(N=28,657)$

\begin{tabular}{llr}
\hline \hline & & $\%$ \\
\hline 1 & Opera/operetta & 4.0 \\
2 & Classical music performance & 7.9 \\
3 & Rock, pop or jazz performance & 29.7 \\
4 & Exhibition or collection of art, photography or sculpture or a & 28.6 \\
& craft exhibition (not craft market) & \\
5 & Event which included video or electronic art & 7.5 \\
6 & Street arts or public art display or installation (art in every- & 16.5 \\
& $\begin{array}{l}\text { day surroundings, or an art work such as sculpture that is } \\
\text { outdoors or in a public place) }\end{array}$ & \\
7 & Carnival or culturally specific festival (for example, Mela, & 14.2 \\
& Baisakhi, Navrati, Feis) & 41.4 \\
\hline \hline
\end{tabular}

Respondents were asked whether they had been to three kinds of musical events and five types of visual arts events in the past 12 months. Table 1 lists the events and shows the percentages of respondents who replied 'yes'. Regarding music, items 1 and 2 are conventional highbrow genres; while the very heterogeneous item 3 refers to a mixture of middlebrow and popular genres. ${ }^{5}$ As regards visual arts, items 4 and 5 refer to highbrow genres, with item 5 being perhaps relatively avant-garde. Items 6 and 7 are visual arts that are found 'on the street', including, say, sculptures of Henry Moore or Barbara Hepworth, but also street graffiti, and displays of ethnic masks and carvings, batik and embroideries, and other folk crafts in cultural festivals. We treat these two items as representing 'popular' forms of visual arts. Finally, item 8 is problematic as it lumps museums and galleries together. As Chan and Goldthorpe (2007b, p. 173) observe, 'some museums-for example, natural history, industrial or local or regional museums - while no doubt displaying many objects of visual interest may not contain much in the way of "works of art" as usually understood.' For this reason, many respondents might see item 8 as representing visual arts of a middling kind.

\footnotetext{
${ }^{5}$ As Alderson et al. (2010, p. 60) put it, “jazz” is a peculiar genre. While today taught at conservatories of music, for instance, as 'high art', it is organically 'lowbrow' and much of the research on jazz, as Peterson and Kern (1996, p. 901) relate, suggests that it is presently 'middlebrow', owing in some part to the fact that popular definitions of jazz vary dramatically from person to person.' As regards pop and rock, it seems reasonable to believe that most respondents would be thinking of mainstream pop and rock rather than particularly 'legitimate' forms of pop and rock when this term is mentioned.
} 
Table 2: Goodness of fit statistics of latent class models

\begin{tabular}{lrrrrrr}
\hline \hline model & \# latent class & $G^{2}$ & $d f$ & $p$ & BIC & $\Delta$ \\
\cline { 1 - 5 } 1 & 1 & 27788.83 & 247 & .000 & 25255.74 & .000 \\
2 & 2 & 2926.49 & 238 & .000 & 485.69 & .046 \\
3 & 3 & 1587.14 & 229 & .000 & -761.36 & .121 \\
4 & 4 & 991.24 & 220 & .000 & -1264.95 & .138 \\
5 & $3^{*}$ & 490.86 & 223 & .000 & -1796.10 & .153 \\
\hline \hline & $1(U)$ & $2(P)$ & $3(O)$ & & \\
relative size & 0.582 & 0.279 & 0.140 & & \\
\cline { 1 - 5 } conditional probability & & & & & \\
opera/operetta & 0.007 & 0.048 & 0.159 & & \\
classical & 0.014 & 0.102 & 0.306 & & \\
rock/pop/jazz & 0.172 & 0.421 & 0.573 & & \\
exhibition & 0.010 & 0.508 & 0.991 & & \\
video arts & 0.014 & 0.060 & 0.358 & & \\
street arts & 0.027 & 0.193 & 0.687 & & \\
carnival & 0.079 & 0.195 & 0.294 & & \\
museum & 0.123 & 0.748 & 0.958 & & \\
\hline \hline
\end{tabular}

Note: $G^{2}$ is the deviance of the model, $d f$ refers to its degree of freedom, $p$ is the probability of Type I error, BIC stands for Bayesian Information Criterion, and $\Delta$ is the percentage of cases misclassified. ${ }^{*}$ In model 5 , six residual local dependence terms are added between the indicators for 'opera and classical', 'pop and video arts', 'pop and street arts', 'pop and carnival', 'street arts' and 'carnival', and between 'video arts' and 'carnival'. 
The binary response to these indicators form a 8-way contingency table with 256 (i.e. $2^{8}$ ) cells which we analyse with latent class models. The goodness of fit statistics of these models are reported in the top panel of Table 2 . None of the latent class models fits the data by the conventional criterion of $5 \%$ type I error. Having said that, model 5 (which postulates three latent classes with specific residual local dependence terms) fits the data considerably better than does model 4 (which has four latent classes), despite being more parsimonious. ${ }^{6}$ Given the very large $N$ of 28,657 , and since model 5 explains $98 \%$ (i.e. $1-\frac{490.86}{27788.83}$ ) of the overall association in the data, we accept this model as providing an adequate summary of the data. ${ }^{7}$

The bottom panel of Table 2 reports the latent class solution under model 5. Members of the largest latent class (comprising 58\% of the sample) are quite unlikely to have attended music or visual art events. Their cultural consumption is largely restricted to one non-highbrow item in each domain, namely, 'rock, pop or jazz' $(p=.17)$ for music and 'museum' $(p=.12)$ for visual arts. Given this, we refer to this latent class as univores $(U)$.

In contrast, members of the smallest latent class (14\% of the sample) are, in relative terms at least, avid cultural consumers. For example, they are more likely than others to have attended classical music concerts $(p=.31$ as opposed to .01 or .10). And, consistent with Peterson and Kern (1996), this group of highbrow culture consumers have no aversion against middlebrow or popular culture. Indeed, they have an even higher probability of attending 'rock, pop or jazz performances' $(p=.57)$. Furthermore, comparing the conditional probabilities of each row of the bottom panel of Table 2, we see that they are most likely of all to consume each of the eight items, highbrow or not. Because their cultural consumption crosses the highbrow-non-highbrow boundaries, we call this latent class omnivores $(O){ }^{8}$

Finally, there is a third latent class that is in-between the other two classes both in terms of its size $(28 \%)$ and the probability of cultural consumption. We refer to this latent class as paucivores $(P)$ because 'pauci', meaning few, is an apt description of the modest amount and limited range of cultural consumption of those in the second latent class. Overall, the re-

\footnotetext{
${ }^{6}$ Compared to model 4 , the deviance $\left(G^{2}\right)$ of model 5 is smaller, and its BIC statistic more negative. At the same time, the degree of freedom of model 5 is 223 , compared to 220 of model 4.

${ }^{7}$ It is well known that with a large $N$, small discrepancies between the model and the data that might be of little sociological importance are often statistically significant (Raftery, 1986). This seems to be the case here.

${ }^{8}$ The latent class solution is based on individual level data and it shows that those who consume highbrow culture are also more likely to consume non-highbrow culture. This result is inconsistent with the composition effect argument.
} 
Table 3: Educational categories for respondents and parents and the collapsed threefold classification

\begin{tabular}{l|l|l}
\hline \hline \multicolumn{1}{c|}{ Parents } & \multicolumn{1}{c|}{ Collapsed } & \multicolumn{1}{c}{ Respondent } \\
\hline 1 Gained a univ/higher degree & 1 Degree & 1 Degree \\
\hline 2 Gained post school qual/cert & & 2 Other higher degree \\
& 2 Intermediate & 3 A-levels etc \\
& & 4 GCSE etc \\
3 Left school with some qual/cert & & 5 Other qual \\
4 Left school with no qual/cert & 3 No qual & 6 No qual \\
5 Did not go to school at all & & \\
\hline \hline
\end{tabular}

sults of our latent class analysis are very similar to those reported by Chan and Goldthorpe (2007a,b) and Bunting et al. (2008). This threefold typology of $U, P$ and $O$ serves as the dependent variable in the analyses below (see also Alderson et al., 2007).

Our main independent variables are the educational attainment of the respondents and that of their parents. ${ }^{9}$ We define social mobility in terms of education rather than social class because education is one of the strongest determinants of cultural consumption. By contrast, social class does not consistently predict cultural consumption once education and social status, in the classical Weberian sense, are taken into account (see e.g. Chan and Goldthorpe, 2007b; Chan, 2010). Focusing on education is also in line with past research (Van Eijck, 1999; Daenekindt and Roose, 2013a,b, 2014; Ultee and de Graaf, 1991).

In Understanding Society, six educational levels for the respondents, but only five levels for the parents, are identified. To achieve comparability, we collapse the two educational classification schemes to three broad levels, namely, 'no qualifications', 'intermediate qualifications', and 'Bachelor's Degree or above' (see Table 3 for details). ${ }^{10}$

Table 4 reports the distribution of respondents by their own educational level and that of their parents. Between the two generations, the share of university graduates has doubled from $14 \%$ to $28 \%$, while the proportion of people without qualifications dropped from $29 \%$ to $17 \%$; and the share of people with intermediate qualifications has stayed roughly stable. Also, just over half $(53 \%)$ of the respondents are educationally immobile (i.e. found in cells on the main diagonal), 35\% are upwardly mobile (found in cells below

\footnotetext{
${ }^{9}$ Parents' education is the higher of father's or mother's education level.

${ }^{10} \mathrm{GCSE}$ is the basic school-leaving certificate, typically gained at age 16 ; A-level is the qualification for university matriculation, typically gained at age 18; other higher degree refers to post-school qualifications below the Bachelor's Degree level.
} 
Table 4: Distribution of respondents by parents' education and own education (cell percentages, $N=25,501$ )

\begin{tabular}{l|ccc|c}
\hline \hline & \multicolumn{3}{|c|}{ respondent } & \\
parents & degree & immediate & no qual & overall \\
\hline degree & 8.4 & 5.7 & 0.4 & 14.4 \\
intermediate & 15.8 & 33.9 & 6.5 & 56.3 \\
no qual & 3.8 & 15.0 & 10.5 & 29.3 \\
\hline overall & 28.0 & 54.6 & 17.4 & 100.0 \\
\hline \hline
\end{tabular}

the main diagonal), and $13 \%$ suffer downward mobility (above the main diagonal). ${ }^{11}$

\section{Diagonal reference model and hypotheses}

Our main analytical tool is the diagonal reference model which was first proposed by Sobel $(1981,1985)$ in a study of social mobility effects on fertility. This class of models has subsequently been used to study a wide range of topics, including class-voting (Weakliem, 1992; Clifford and Heath, 1993), life satisfaction (Marshall and Firth, 1999), class identity (Sobel et al., 2004), parenting practices (Van der Slik et al., 2002), intergenerational proximity (Chan and Ermisch, 2015), and cultural consumption (Ultee and de Graaf, 1991; Daenekindt and Roose, 2013a,b, 2014; Coulangeon, 2015). In this paper, our dependent variable is the trichotomous latent class membership $(U, P$ or $O)$. The baseline diagonal reference model can be represented as follows:

$$
\log \left(\frac{\pi_{r c}^{V}}{\pi_{r c}^{U}}\right)=w^{V} \log \left(\frac{\pi_{r r}^{V}}{\pi_{r r}^{U}}\right)+\left(1-w^{V}\right) \log \left(\frac{\pi_{c c}^{V}}{\pi_{c c}^{U}}\right) .
$$

In model $1, V$ is a placeholder, standing for either $P$ (paucivores) or $O$ (omnivores); ${ }^{12} U$ stands for the univores; $\pi_{r c}^{V}$ is the probability of individuals with parental educational level $r$ and own educational level $c$ being a $V$; $w^{V}$ measures the relative importance of parents' education in determining cultural consumption, with $0 \leq w^{V} \leq 1$; and $1-w^{V}$ measures the relative weight of respondent's own education. In other words, under this model, the

\footnotetext{
${ }^{11}$ We have repeated our analyses for three age cohorts separately. The results of these cohort-specific analyses, corresponding to Tables 4 and 5 of the main text, are reported in Appendix A.

${ }^{12}$ In other words, there are two sub-equations under model 1 , representing the ' $P$ v $U$ ' and ' $O \mathrm{v} U$ ' contrasts respectively. These sub-equations are estimated jointly.
} 


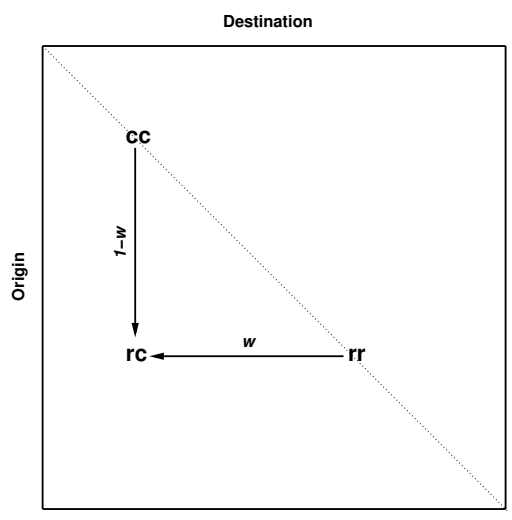

Figure 1: Intuition of the diagonal reference model

logit of someone from origin $r$ and in destination $c$ being a $V$ rather than a $U$ is constrained to be a weighted average of the corresponding logits of immobile people with educational levels $r$ and $c$ respectively.

The idea is that socially immobile individuals are the 'pure types'. They set the taste and consumption standards for their educational levels. Socially mobile individuals, taking behavioural cues from the immobiles in the relevant origin and destination categories, combine these reference standards as a weighted average. Figure 1 illustrates this intuition diagrammatically. ${ }^{13}$

Recall that the first version of the social mobility argument (i.e. the composition effect argument) says that the cultural consumption behaviour of individuals is completely determined by their social origin. This implies that $w^{V}=1$, and model 1 is reduced to the following.

$$
\log \left(\frac{\pi_{r c}^{V}}{\pi_{r c}^{U}}\right)=\log \left(\frac{\pi_{r r}^{V}}{\pi_{r r}^{U}}\right) .
$$

As model 2 is nested within model 1, we could compare their fit to the data using the likelihood ratio test.

Hypothesis 1: (if the composition effect argument holds) model 2 fits that data as well as does model 1.

If it turns out that $w^{V}$ is significantly different from 1 (or, equivalently, that the fit of model 2 to the data is significantly worse than that of model 1 ), then both origin and destination influence individual behaviour. But this is not necessarily empirical support for the second version of the social mobility argument (i.e. the diverse exposure argument). In fact, if model

\footnotetext{
${ }^{13}$ We use the R 'gnm' package to fit diagonal reference models (Turner and Firth, 2011).
} 
1 fits the data, then the diverse exposure argument cannot be valid. To see this, recall that this argument requires socially mobile individuals to be more omnivorous than those who are intergenerationally stable in advantaged positions. Now, the diagonal reference model constrains the logit of mobile individuals (say, being $O$ rather than $U$ ) to be a weighted average of the logits of the two reference immobile groups. Because $0 \leq w^{V} \leq 1$, the logit of the socially mobile cannot be greater than the larger of the two reference logits; nor can it be less than the smaller of the two. ${ }^{14}$ And since probability is a monotonically increasing function of the logit, one implication of model 1 is that socially mobile individuals cannot be more omnivorous than immobile individuals in the higher reference education category. ${ }^{15}$ In other words, model 1 is not consistent with the diverse exposure argument. Conversely put, if the diverse exposure argument is true, then model 1 would fail to fit the data.

Hypothesis 2: (if the diverse exposure argument holds) model 1 does not fit the data.

The third version of social mobility argument requires the relative weights of origin and destination to differ between upwardly mobile and downwardly mobile individuals. This asymmetry can be parameterised as follows:

$$
\log \left(\frac{\pi_{r c}^{V}}{\pi_{r c}^{U}}\right)=\left(w^{V}+\delta^{V}\right) \log \left(\frac{\pi_{r r}^{V}}{\pi_{r r}^{U}}\right)+\left(1-\left(w^{V}+\delta^{V}\right)\right) \log \left(\frac{\pi_{c c}^{V}}{\pi_{c c}^{U}}\right),
$$

where $\delta^{V}=0$ if $c \geq r$ (i.e. if respondent is not better qualified than parents). In other words, model 3 returns two sets of weight parameters: $w^{V^{\prime}}=w^{V}+\delta^{V}$ for upwardly mobile individuals, and $w^{V}$ for downwardly mobile individuals.

Hypothesis 3: (if the asymmetry argument holds) model 3 fits the data better than does model 1 .

Models 1, 2 and 3 are models for aggregate data. Comparing them will help us identify, in broad terms, an appropriate model for our data. But we will also analyse the data at the individual-level. This is important because previous research has identified several determinants of cultural consumption other than education, including social status, age, gender, parental status, ethnicity, and location (see e.g. Chan and Goldthorpe, 2007a,b). We need

\footnotetext{
${ }^{14}$ That is, let $\gamma_{r c}$ be the logit of the $r c$-th cell, model 1 requires that $\min \left(\gamma_{r r}, \gamma_{c c}\right) \leq$ $\gamma_{r c} \leq \max \left(\gamma_{r r}, \gamma_{c c}\right)$.

${ }^{15}$ Past research has consistently shown that better educated people are more omnivorous. See also Table 6 below.
} 
to check whether the results of our aggregate analyses remain robust after we take these covariates into account. For example, cultural consumption has been found to be higher in London than in many regions of the country, possibly reflecting the concentration of concert venues, galleries, museums, etc. in London. At the same time, a disproportionate share of graduate jobs in the UK is London-based. So a critic might argue that the large education effects revealed in the aggregate analysis might, to some degree, reflect the greater opportunities for cultural consumption in London compared to the rest of the UK. To address this and similar concerns, we incorporate location and other determinants of cultural consumption in our diagonal reference models as follows.

$$
\begin{aligned}
& \log \left(\frac{\pi_{r c}^{V}}{\pi_{r c}^{U}}\right)=w^{V} \log \left(\frac{\pi_{r r}^{V}}{\pi_{r r}^{U}}\right)+\left(1-w^{V}\right) \log \left(\frac{\pi_{r r}^{V}}{\pi_{r r}^{U}}\right)+\boldsymbol{x}^{\prime} \boldsymbol{\beta}^{V} \\
& \log \left(\frac{\pi_{r c}^{V}}{\pi_{r c}^{U}}\right)=\log \left(\frac{\pi_{r r}^{V}}{\pi_{r r}^{U}}\right)+\boldsymbol{x}^{\prime} \boldsymbol{\beta}^{V} \\
& \log \left(\frac{\pi_{r c}^{V}}{\pi_{r c}^{U}}\right)=\left(w^{V}+\delta^{V}\right) \log \left(\frac{\pi_{r r}^{V}}{\pi_{r r}^{U}}\right)+\left(1-\left(w^{V}+\delta^{V}\right)\right) \log \left(\frac{\pi_{c c}^{V}}{\pi_{c c}^{U}}\right)+\boldsymbol{x}^{\prime} \boldsymbol{\beta}^{V}
\end{aligned}
$$

where $\boldsymbol{x}$ is a vector of covariates and $\boldsymbol{\beta}^{\boldsymbol{V}}$ is the corresponding vector of parameters. Models 4, 5, 6 correspond to models 1, 2 and 3 respectively. Descriptive statistics of the covariates are reported in Table ?? in Appendix C.

\section{Results}

Table 5 reports the goodness of fit statistics of the diagonal reference models. Briefly, on the left-hand panel, $G^{2}$ is the likelihood-ratio $\chi^{2}$ statistic or the model's deviance. It describes how well or poorly the model fits the observed data, with smaller $G^{2}$ indicating a better fit. Residual degrees of freedom are denoted by $d f$; more parsimonious models have higher $d f$. Finally, $p$ is the probability of Type I error. That is to say, assuming that the model in question is the true model, $p$ tells us how likely it is to draw a sample that gives us a deviance that is at least as large as the one obtained. The righthand panel reports the likelihood ratio tests for nested models. Here, $p$ tells us how likely it is that the reduction in deviance $\left(\Delta G^{2}\right)$ of the more complex model is due to chance, given its extra parameters (and the corresponding loss of degrees of freedom, $\Delta d f)$. 
Table 5: Goodness of fit statistics of diagonal reference models

\begin{tabular}{crrc|crrr}
\hline \hline & & & \multicolumn{2}{|c}{ model } & & & \\
model & $G^{2}$ & $d f$ & $p$ & comparison & $\Delta G^{2}$ & $\Delta d f$ & $p$ \\
\hline 1 & 6.47 & 10 & 0.77 & & & & \\
2 & 2396.24 & 12 & 0.00 & $2-1$ & 2389.77 & 2 & 0.00 \\
3 & 1.07 & 8 & 1.00 & $1-3$ & 5.40 & 2 & 0.07 \\
\hline \hline
\end{tabular}

Note: $G^{2}$ is the deviance of the model, $d f$ refers to its degree of freedom, and $p$ is the probability of Type I error.

The first thing to note about Table 5 is that, contrary to Hypothesis 2, our baseline model 1 actually fits the data very well. This is inconsistent with the diverse exposure argument. That is to say, so far as music and visual arts consumption in the UK is concerned, first-generation university graduates are not more omnivorous than second-generation graduates.

This is shown graphically in Figure 2 where we plot the predicted probability, under model 1 , of being an omnivore for various combinations of respondent's education and parent's education. Consider the three columns where the respondents are university graduates. The tallest column in Figure 2, refers to second-generation graduates (i.e. both the respondent and the parent are university graduates), $35 \%$ of whom are omnivores. The corresponding probabilities for first-generation graduates are $26 \%$ (if their parents have intermediate qualifications) and 20\% (if their parents have no qualifications). ${ }^{16}$ This confirms that upwardly mobile respondents are less omnivorous than second-generation graduates. ${ }^{17}$

As regards downward mobility, compare the three columns where the parents are university graduates. As noted already, 35\% of these respondents would be omnivores if they themselves have a university degree, dropping to $14 \%$ and $6 \%$ respectively, if they have intermediate qualifications or no qualifications. As with upward mobility, the experience of downward mobility does not make people more omnivorous.

Under model $1, w^{P}=.252($ s.e. $=.020)$ and $w^{O}=.269($ s.e. $=.015)$.

\footnotetext{
${ }^{16}$ The gradient in the observed data is very similar: among university graduates, the probability of being an omnivore, in descending order of parental education, are $.35, .27$ and .21 respectively. The close resemblance between the observed and predicted probabilities is not surprising given that model 1 fits the data very well.

${ }^{17}$ If the diverse exposure argument is true, we would see an opposite gradient in the observed data, i.e. there would be proportionally more omnivores among first-generation university graduates than among second-generation graduates.
} 


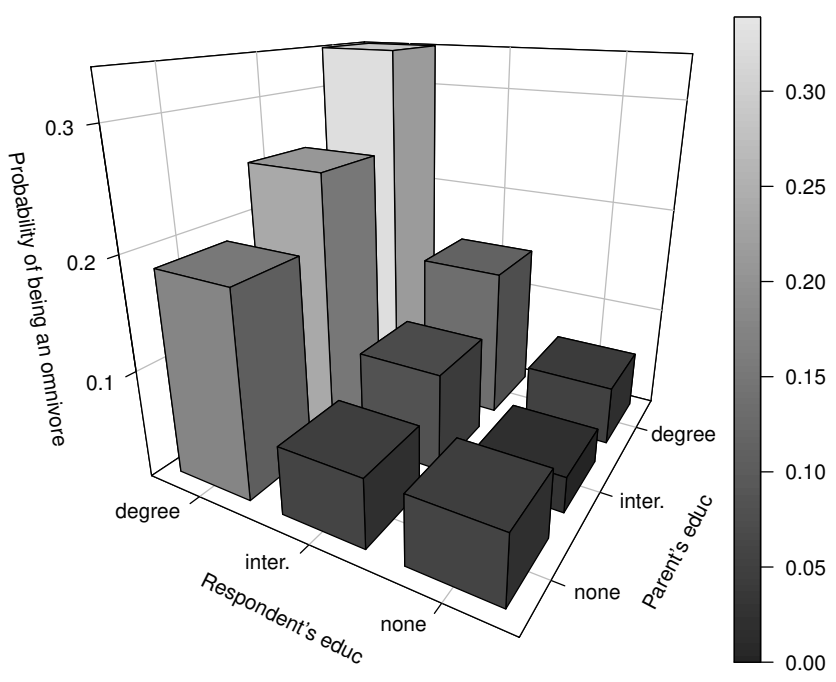

Figure 2: Predicted probability under model 1 of being a cultural omnivore by respondent's and parent's education

These estimates strongly suggest that both $w^{P}$ and $w^{O}$ are significantly different from one. ${ }^{18}$ Furthermore, it can be seen from Table 5 that the fit of model 2 (which implies that $w^{V}=1$ ) to the data is very much worse than that of model 1. Indeed, model 2 does not fit the data at all. Thus, we also reject Hypothesis 1 and the composition effect argument.

Model 3 includes the asymmetry parameter and thus allows the relative weights of origin and destination to differ between upwardly mobile and downwardly mobile individuals. Model 3 also fits the data well. ${ }^{19}$ And since models 1 and 3 are nested, their fit to the data can be compared formally using the likelihood ratio test. Table 5 shows that, compared to model 1 , the deviance of model 3 is reduced by 5.40 for 2 degrees of freedom, which is marginally not a significant improvement in model fit $(p=.07)$. Thus, the evidence to support Hypothesis 3 or the asymmetry argument is not very strong. ${ }^{20}$ Put differently, there is no need to assume that the relative weights

\footnotetext{
${ }^{18}$ The $95 \%$ confidence interval of $w^{P}$ is $(.213, .292)$ and that of $w^{O}$ is $(.239, .298)$.

${ }^{19}$ Under model 3 , the weight parameters for the upwardly mobile are $w^{P^{\prime}}=.212$ (s.e. $=$ $.028), w^{O^{\prime}}=.246,($ s.e. $=.020)$; for the downwardly mobile, $w^{P}=.330($ s.e. $=.044)$ and $w^{O}=.318$ (s.e. $\left.=.035\right)$.
}

${ }^{20}$ Further analysis by cohort suggests that asymmetry in the weight parameter is re- 
of origin and destination are different between the upwardly mobile and the downwardly mobile. ${ }^{21}$

\subsection{Diagonal reference models with covariates}

The results of our analyses so far fail to support any of the three versions of the social mobility argument. To investigate further, we now consider diagonal reference models with covariates, i.e. models 4,5 and 6 . Their deviance $\left(G^{2}\right)$ are 33,599 (model $4, d f=36,408$ ), 34,570 (model 5, $d f=$ $36,414$ ) and 33,597 (model $6, d f=36,406) .{ }^{22}$ Similar to what we saw in Table 5 , model 5 , which assumes that $w^{V}=1$, fits the data much more poorly than does model 4 , which allows $w^{V}$ to vary freely. This does not support the composition effect argument. ${ }^{23}$ As regards the asymmetry argument, we note that the deviance of model 6 is only marginally smaller than that of model 4 : a difference of 2 for two degrees of freedom is not a significant improvement in model fit. Thus, as before, we prefer the more parsimonious model 4 to the more complex model 6 , and conclude that there is no evidence to support the asymmetry argument.

The parameter estimates under model 4, reported in Table 6, are largely consistent with past research (e.g. Chan and Goldthorpe, 2007a,b; Bunting et al., 2008). Thus, older respondents, and those with higher income or of higher social status are more likely to be omnivores or paucivores rather than univores; and they are more likely to be omnivores rather than paucivores. The opposite holds for ethnic minorities and for respondents living outside London. As noted in Section 3, the regional differences are probably due to the greater opportunities for cultural consumption in London. As regards the children parameters, consistently negative and significant effects are observed for respondents with children aged $0-4$, which is probably related to the especially demanding care responsibility for young children.

Coming to educational attainment, we see that compared with university graduates, individuals with intermediate or no qualifications are much less likely to be paucivores or omnivores rather than univores, and they are less likely to be omnivores rather than paucivores. As noted above, the critical

stricted to the youngest cohort (see Table ?? in Appendix A).

${ }^{21}$ As a sensitivity test, we have repeated our analysis using the number of cultural items consumed as the dependent variable. This gives the same substantive conclusions regarding the three hypotheses (see Appendix B).

${ }^{22}$ Because model 4, 5 and 6 are based on individual level data, their deviances are much larger than those of models 1,2 and 3 .

${ }^{23}$ Under model $4, w^{P}=.301($ s.e. $=.027)$ and $w^{O}=.358($ s.e. $=.018)$. These estimates also strongly suggest the weight parameters are significantly different from 1. 
Table 6: Estimates of covariates under model 4

\begin{tabular}{lcc|cc|cc}
\hline \hline & \multicolumn{2}{c}{$P \mathrm{v} U$} & \multicolumn{2}{c|}{$O \mathrm{v} U$} & \multicolumn{2}{c}{$O \mathrm{v} P$} \\
& $\beta$ & s.e. & $\beta$ & s.e. & $\beta$ & s.e. \\
\hline age & $0.019^{* *}$ & 0.001 & $0.029^{* *}$ & 0.002 & $0.010^{* *}$ & 0.002 \\
\hline female & -0.063 & 0.037 & $-0.147^{* *}$ & 0.046 & -0.084 & 0.048 \\
\hdashline single & $0.126^{*}$ & 0.055 & 0.123 & 0.069 & -0.002 & 0.071 \\
div/sep/wid & $0.155^{*}$ & 0.069 & 0.054 & 0.090 & -0.101 & 0.092 \\
\hline child 0-4 & $-0.381^{* *}$ & 0.053 & $-0.732^{* *}$ & 0.073 & $-0.350^{* *}$ & 0.076 \\
child 5-11 & $0.148^{* *}$ & 0.047 & -0.022 & 0.063 & $-0.171^{*}$ & 0.065 \\
child 12-15 & -0.031 & 0.052 & -0.080 & 0.069 & -0.049 & 0.071 \\
black & $-0.775^{* *}$ & 0.094 & $-1.646^{* *}$ & 0.146 & $-0.870^{* *}$ & 0.154 \\
asian & $-0.905^{* *}$ & 0.143 & $-1.849^{* *}$ & 0.226 & $-0.944^{* *}$ & 0.240 \\
others & -0.193 & 0.119 & $-0.439^{* *}$ & 0.151 & -0.245 & 0.155 \\
income & $0.150^{* *}$ & 0.030 & $0.113^{* *}$ & 0.038 & -0.036 & 0.040 \\
status & $0.798^{* *}$ & 0.059 & $1.232^{* *}$ & 0.077 & $0.433^{* *}$ & 0.082 \\
North East & -0.138 & 0.107 & $-0.292^{*}$ & 0.128 & -0.153 & 0.133 \\
North West & $-0.356^{* *}$ & 0.078 & $-0.764^{* *}$ & 0.095 & $-0.408^{* *}$ & 0.097 \\
Yorkshire & $-0.267^{* *}$ & 0.085 & $-0.444^{* *}$ & 0.100 & -0.176 & 0.104 \\
East Midlands & $-0.458^{* *}$ & 0.089 & $-0.668^{* *}$ & 0.108 & -0.210 & 0.114 \\
West Midlands & $-0.449^{* *}$ & 0.083 & $-0.978^{* *}$ & 0.107 & $-0.529^{* *}$ & 0.111 \\
East of Eng & $-0.331^{* *}$ & 0.079 & $-0.878^{* *}$ & 0.099 & $-0.547^{* *}$ & 0.101 \\
South East & -0.033 & 0.071 & $-0.454^{* *}$ & 0.084 & $-0.421^{* *}$ & 0.084 \\
South West & -0.109 & 0.082 & $-0.493^{* *}$ & 0.100 & $-0.383^{* *}$ & 0.101 \\
Wales & $-0.440^{* *}$ & 0.102 & $-1.142^{* *}$ & 0.143 & $-0.702^{* *}$ & 0.149 \\
Scotland & -0.107 & 0.082 & $-0.334^{* *}$ & 0.097 & -0.227 & 0.098 \\
N.Ireland & $-0.497^{* *}$ & 0.125 & $-1.213^{* *}$ & 0.183 & $-0.716^{* *}$ & 0.192 \\
intermediate & $-1.023^{* *}$ & 0.060 & $-1.943^{* *}$ & 0.073 & $-0.919^{* *}$ & 0.074 \\
no qual & $-1.990^{* *}$ & 0.089 & $-3.663^{* *}$ & 0.132 & $-1.676^{* *}$ & 0.136 \\
\hline \hline
\end{tabular}

Note: ${ }^{*} p<.05,{ }^{* *} p<.01$; reference category: ${ }^{a}$ couple,${ }^{b}$ childless, ${ }^{c}$ white, ${ }^{d}$ London, ${ }^{e}$ university degree. 
test for the diverse exposure argument is whether, under our preferred model 4, first-generation graduates are more omnivorous than second-generation graduates. To address this question and also to give a sense of the substantive magnitude of the various parameters, Figure 3 reports the predicted probabilities of latent class membership under model 4 for different sets of covariate values.

Consider a 40-year-old white woman with a monthly household income of $£ 3,000$. She is childless, and she lives in London with a partner. ${ }^{24}$ In scenario 1 , we further assume that she is a second-generation university graduate and works as a Higher Professional (e.g. an accountant), which is at the top of the status scale of Chan and Goldthorpe (2004). Under this scenario, the probability of her being an omnivore is $57 \%$. But if she works as a Manager or Proprietor in Services (e.g. a hotel manager) which is of middling status, while all other covariates remain unchanged (scenario 2), then her probability of being an omnivore stands at 46\%. The difference between scenarios 1 and 2 gives us a sense of the magnitude of the status effect. ${ }^{25}$

In scenarios 3 through 5, our hypothetical woman still works as a Manager or Proprietor in Services. But we vary her educational level and that of her parents. If both she and her parents have no qualifications (scenario 3), then her probability of being an omnivore drops to just $4 \%$. Clearly, the education effect is, in substantive terms, much larger than the status effect.

In scenario 4, our hypothetical woman achieves upward educational mobility. That is, her parents have no qualifications, but she is a university graduate. Under this scenario, her probability of being an omnivore is $24 \%$. In the case of downward mobility (i.e. she has no qualifications, but her parents are university graduates, scenario 5), the probability is $13 \%$. The important point to note here is that where our hypothetical woman is educationally mobile, either upward or downward, she is considerably less likely to be an omnivore, compared to the situation where she is a second-generation university graduate (i.e. compare scenarios 4 and 5 with scenario 2). Overall, the results of the diagonal reference models with covariates point to the same conclusions as those without covariates.

\footnotetext{
${ }^{24}$ These are mean or modal values of the covariates (or very nearly so). See Table ?? in Appendix $\mathrm{C}$ for details.

${ }^{25}$ The status effect between scenarios 1 and 2 refers to about half of the overall range of the status scale. We choose to contrast Higher Professional with Manager or Proprietor in Services rather than with General Labourer (which is at the bottom of the status scale) because there are very few second-generation university graduates working as General Labourers, making that combination of covariate values unlikely.
} 


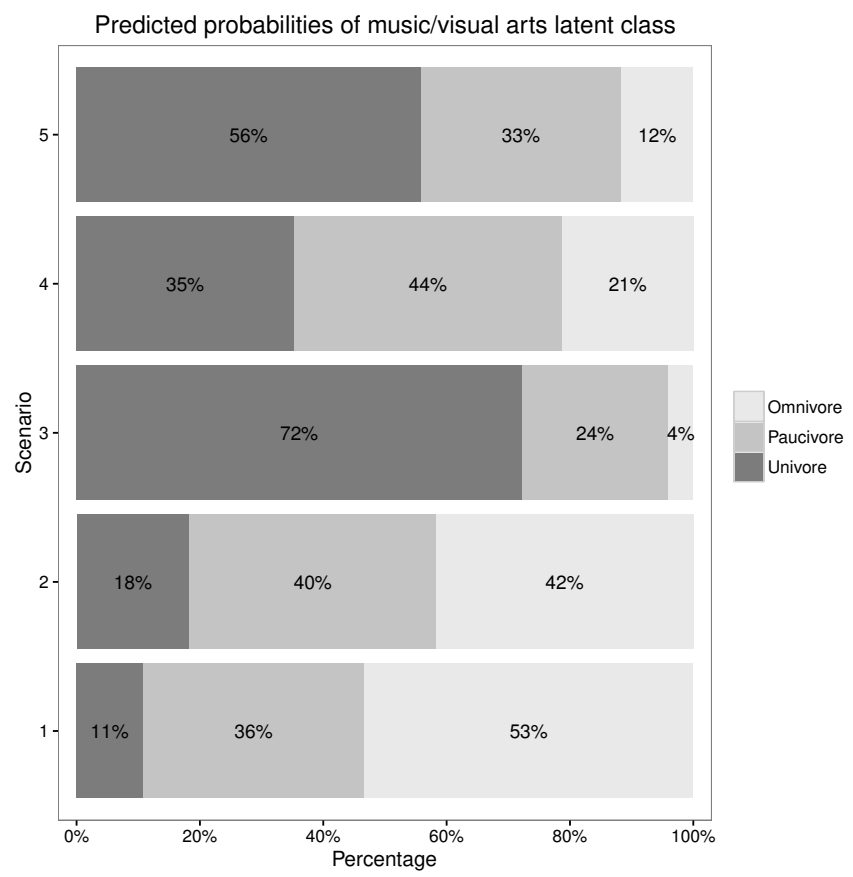

Note: occupation and education of a hypothetical woman set as follows: scenario 1: Higher Professional, graduate (own), graduate (parents) scenario 2: Manager or Proprietor in Services, graduate (own), graduate (parents) scenario 3: Manager or Proprietor in Services, no qual (own), no qual (parents) scenario 4: Manager or Proprietor in Services, graduate (own), no qual (parents) scenario 5: Manager or Proprietor in Services, no qual (own), graduate (parents)

Figure 3: Predicted probabilities of latent class membership under model 4 


\section{Summary and discussion}

Many scholars see social mobility as playing a key role in explaining the emergence of cultural omnivores. In this paper, we discuss three versions of the social mobility argument and show that none of them receives empirical support from recent survey data on cultural consumption in the UK.

To elaborate, music and visual arts consumption is very far from being determined by primary socialisation at the family of origin. Instead, the educational attainment of individuals carries about three times as much weight as their parents' education. (When covariates are taken into account, the ratio is lower, but is still at the level of about two-to-one.) This is inconsistent with the composition effect argument. Furthermore, as this three-to-one (or two-to-one) ratio applies equally to both upwardly mobile and downwardly mobile individuals, there is no support for the asymmetry or status maximisation argument. ${ }^{26}$ Finally, socially mobile individuals, whether they move upwards or downwards, are actually less omnivorous than those who are intergenerationally stable in advantaged positions. In particular, firstgeneration university graduates are less omnivorous than second-generation graduates. This contradicts the diverse exposure argument.

In the introductory section of this paper, we argue that cultural democratisation and social mobility are two complementary social forces that might explain the emergence of cultural omnivores. Given the lack of empirical support for the latter, it seems to us that scholars should turn their attention to the former as a more promising avenue for further exploration. We recognise that this is a considerable challenge, as the long-term social-structural, cultural, and institutional changes that we briefly review in Section 1 are many and varied; and not all of them will apply with equal validity in all countries. So careful historical and institutional analyses that are sensitive to cross-national differences as well as similarities will be needed to disentangle and assess the variegated claims.

Nonetheless, as noted above, these claims of cultural democratisation all imply that cultural boundaries are weakening. We do not deny that the distinctions between highbrow, middlebrow and lowbrow cultures still exist. For example, most people would still regard opera but not street graffiti as

\footnotetext{
${ }^{26}$ Educational attainment might influence cultural consumption through two quite different but complementary channels: a social status effect, and a cognitive ability effect (see e.g. Notten et al., 2015). Because the cognitive ability of individuals are probably better measured by their own educational attainment than by their parent's education, the three-to-one ratio of the weight parameter lends some support to the cognitive ability argument. But it should be noted the results reported in this paper are consistent with either interpretation. In practice, both factors are probably at work.
} 
highbrow culture. But there is a good deal of cultural crossover. Some opera singers release pop albums, while the work of some graffiti artists is exhibited in art galleries and sold in auction houses at fantastic prices.

The blurring of cultural boundaries is mirrored by the declining significance of high culture as a status marker. Consider the founding of the Metropolitan Opera in the 1880s as recounted by Beckert (2001, p. 247). After Vanderbilt, the railroad magnate, was snubbed by the then dominant New York Academy of Music, he and other industrialist- and financier-upstarts in New York founded the Metropolitan Opera and eventually drove the New York Academy out of business. If a private box in an opera house was the required statement of acceptance into 'society' of that era, it does not seem to be the case any more. The rich and powerful of today certainly still flaunt their wealth. But they do not have to do so through sponsoring high culture. Instead, owning a sports team or conspicuous consumption of material luxury such as private jets or superyachts have become de rigueur (Frank, 1999).

\section{References}

Alderson, A. S., Junisbai, A., and Heacock, I. (2007). Social status and cultural consumption in the United States. Poetics, 35(2/3), 191-212.

Alderson, A. S., Heacock, I., and Junisbai, A. (2010). Social stratification and musical consumption: Highbrow/middlebrow in the United States. In T. W. Chan, editor, Social Status and Cultural Consumption: A Comparative Study of Six Countries. Cambridge University Press, Cambridge.

Beckert, S. (2001). The Monied Metropolis: New York City and the Consolidation of the American Bourgeoisie, 1850-1986. Cambridge University Press, Cambridge.

Bennett, T., Savage, M., Silva, E., Warde, A., Gayo-Cal, M., and Wright, D. (2009). Culture, Class and Distinction. Routledge, London.

Bunting, C., Chan, T. W., Goldthorpe, J., Keaney, E., and Oskala, A. (2008). From indifference to enthusiasm: patterns of arts attendance in England. Research report, Arts Council England, London.

Chan, T. W., editor (2010). Social Status and Cultural Consumption. Cambridge University Press, Cambridge.

Chan, T. W. and Ermisch, J. (2015). Proximity of couples to parents: influences of gender, labour market. Demography, 52(2), 379-399. 
Chan, T. W. and Goldthorpe, J. H. (2004). Is there a status order in contemporary British society? Evidence from the occupational structure of friendship. European Sociological Review, 20(5), 383-401.

Chan, T. W. and Goldthorpe, J. H. (2007a). Social stratification and cultural consumption: Music in England. European Sociological Review, 23(1), 119.

Chan, T. W. and Goldthorpe, J. H. (2007b). Social stratification and cultural conumption: the visual arts in England. Poetics, 35(2/3), 168-190.

Clifford, P. and Heath, A. F. (1993). The political consequences of social mobility. Journal of the Royal Statistical Society, Series A, 156(1), 51-61.

Coulangeon, P. (2015). Social mobility and musical tastes: a reappraisal of the soical meaning of taste eclecticism. Poetics, 51, 54-68.

Cox, D. R. (1990). Role of models in statistical analysis. Statistical Science, 5(2), 169-174.

Daenekindt, S. and Roose, H. (2013a). Cultural chameleons: social mobility and cultural practices in the private and public sphere. Acta Sociologica, 56(4), 309-324.

Daenekindt, S. and Roose, H. (2013b). A Mise-en-scéne of the shattered habitus: the effect of social mobility on aesthetic dispositions towards film. European Sociological Review, 29(1), 48-59.

Daenekindt, S. and Roose, H. (2014). Social mobility and cultural dissonance. Poetics, 42, 82-97.

Duncan, O. D. (1966). Methodological issues in the analysis of social mobility. In N. J. Smelser and S. M. Lipset, editors, Social Structure and Mobility in Economic Development, pages 51-97. University of California Press, Berkeley.

Erikson, R. and Goldthorpe, J. H. (1992). The Constant Flux: A Study of Class Mobility in Industrial Societies. Clarendon Press, Oxford.

Frank, R. H. (1999). Luxury Fever: Why Money Fails to Satisfy in an Era of Excess. Free Press, New York.

Friedman, S. (2012). Cultural omnivores or culturally homeless? Exploring the shifting cultural identities of the upwardly mobile. Poetics, 40, 467489. 
Hope, K. (1975). Models of status inconsistency and soical mobility effects. American Sociological Review, 40, 322-343.

Hope, K. (1981). Vertical mobility in Britain. Sociology, 15, 19-55.

Houle, J. N. and Martin, M. A. (2011). Does intergenerational mobility shape psychological distress? Sorokin revisited. Research in Social Stratification and Mobility, 29, 193-203.

Inglehart, R. (1990). Cultural Shifts in Advanced Industrial Societies. Princeton University Press, Princeton.

Lahire, B. (2008). The individual and the mixing of genres: cultural dissonance and self-distinction. Poetics, 36, 166-188.

López-Sintas, J. and García-Álvarez, E. (2002). Omnivores show up again: the segmentation of cultural consumers in Spanish social space. European Sociological Review, 18(3), 353-368.

Marshall, G. and Firth, D. (1999). Social mobility and personal satisfaction: evidence from ten countries. British Journal of Sociology, 50(1), 28-48.

Notten, N., Lancee, B., van de Werfhorst, H. G., and Ganzeboom, H. B. G. (2015). Educational stratification in cultural participation: cognitive competence or status motivation? Journal of Cultural Economics, 39, 177-203.

Peterson, R. A. (1992). Understanding audience segmentation: from elite and mass to omnivore and univore. Poetics, 21(4), 243-258.

Peterson, R. A. and Kern, R. M. (1996). Changing highbrow taste: from snob to omnivore. American Sociological Review, 61(5), 900-907.

Peterson, R. A. and Simkus, A. (1992). How musical tastes mark occupational status groups. In M. Lamont and M. Fournier, editors, Cultivating Differences: Symbolic Boundaries and the Making of Inequality, chapter Seven, pages 152-186. University of Chicago Press, Chicago.

Raftery, A. E. (1986). Choosing models for cross-classifications. American Sociological Review, 51(1), 145-146.

Runciman, W. G. (1997). Applied Social Theory, volume 3 of A Treatise On Social Theory. Cambridge University Press, Cambridge.

Sobel, M. E. (1981). Diagonal mobility models: a substantively motivated class of designs for the analysis of mobility effects. American Sociological Review, 46, 893-906. 
Sobel, M. E. (1985). Social mobility and fertility revisited: some new models for the analysis of the mobility effects hypothesis. American Sociological Review, 50, 699-712.

Sobel, M. E., de Graaf, N. D., Heath, A., and Zou, Y. (2004). Men matter more: the social class identity of married British women, 1985-1991. Journal of the Royal Statistical Society, Series A, 167(1), 37-52.

Turner, H. and Firth, D. (2011). Generalized nonlinear models in R: an overview of the gnm package. $\mathrm{R}$ package version 1.0-1.

Ultee, W. C. and de Graaf, N. D. (1991). Burgerlijke cultuur en culturele burgers. In A. J. A. Felling and J. Peters, editors, Cultuur en Sociale Wetenschapen, Beschouwingen en Empirische Studies, pages 227248. ITS, Nijmegen.

Van der Slik, F. W. P., de Graaf, N. D., and Gerris, J. R. M. (2002). Conformity to parental rules: asymmetric influences of father's and mother's levels of education. European Sociologicl Review, 18(4), 489-502.

Van Eijck, K. (1999). Socialization, education, and lifestyle: how social mobility increases the cultural heterogeneity of status groups. Poetics, 26, 309-328.

Van Eijck, K. (2001). Social differentiation in musical taste patterns. Social Forces, 79(3), 1163-1184.

Weakliem, D. L. (1992). Does social mobility affect political behaviour? European Sociological Review, 8(2), 153-165. 